\title{
Saúde mental em contextos indígenas: Escassez de pesquisas brasileiras, invisibilidade das diferenças
}

Marianna Queiróz Batista. Secretaria de Estado de Educação do Distrito Federal. Valeska Zanello. Universidade de Brasília.

\section{Resumo}

O presente trabalho teve como objetivo realizar um levantamento de artigos produzidos sobre o tema saúde mental em contextos indígenas entre os anos de 1999 e 2012 nas principais plataformas científicas brasileiras (SciELO e BVS-PSI). Foram utilizados três grupos de descritores, perfazendo 62 buscas, as quais encontraram 5510 resultados, dos quais, depois de analisados, sobraram apenas 14 artigos. Foram levantados dados quanto à distribuição por ano de publicação, tema e objeto da pesquisa, etnia e região geográfica abrangida, participação ou não dos profissionais de psicologia no estudo; entre outros. Além disso, foi avaliado se os conceitos de saúde mental e indígena foram ou não problematizados, levando-se em consideração a alteridade e diversidade cultural destes povos. Conclui-se que as pesquisas são incipientes e carecem de reflexão epistemológica para fundamentar a complexidade desse diálogo intercultural que discute saberes advindos de referenciais originalmente tão distintos.

Palavras-chave: saúde mental; índios; grupos étnicos.

\section{Abstract}

Mental health in indigenous contexts: Scarcity of Brazilian researches, invisibility of differences. This study aimed to conduct a survey of articles produced on the topic mental health in indigenous contexts between the years 1999 and 2012 in the main Brazilian scientific platforms (SciELO and BVS-PSI). Three groups of descriptors were used, totaling 62 searches, which found 5510 results. Of these, only 14 articles remained after analysis. Data was collected on the distribution by year of publication, subject and object of research, ethnicity and geographic region covered, participation or not of psychology professionals in the study, among others. Also, we assessed whether the concepts of mental health and indigenous were or not problematized, taking into account the alterity and cultural diversity of these people. It was concluded that the researches are incipient and lack on epistemological reflection to support the complexity of this intercultural dialogue, which discusses knowledge arising from references that are originally so distinct.

Keywords: mental health; Indians; ethnic groups.

\section{Resumen}

La salud mental en contextos indígenas: La escassez de la investigación brasileña, la invisibilidad de las diferencias. Este estudio tuvo como objetivo realizar un estudio de los artículos producidos en la salud mental tema en contextos indígenas entre los años 1999 y 2012 en las principales plataformas científicas brasileñas (SciELO y BVS-Psi). Se han usado tres grupos de descriptores, por un total de 62 registros, que encontraron 5510 resultados, de los que, tras el análisis, siendo sólo 14 artículos. Se recogieron datos sobre la distribución por año de publicación, sujeto y objeto de la investigación, el origen étnico y la región geográfica cubierta, la participación o no de profesionales de la psicología en el estudio; entre otros. Además, se evaluó si los conceptos de salud mental e indígenas fueron o no problematizados teniendo en cuenta la alteridad y la diversidad cultural de estas personas. En conclusión, la investigación es incipiente y la falta de reflexión epistemológica para apoyar la complejidad del diálogo intercultural discutir conocimientos derivados de las referencias originalmente como distintos.

Palabras clave: salud mental; índios; grupos etnicos. 
Segundo o censo de 2010 do IBGE, a população indígena no Brasil é estimada em 896.900 mil indivíduos, o que corresponde a $0,4 \%$ da população brasileira. De acordo com dados da Fundação Nacional do Índio (FUNAI) e do Instituto Socioambiental (ISA), a população indígena no Brasil está distribuída em 240 etnias, 683 terras indígenas (além de algumas áreas urbanas) e falantes de 200 línguas, aproximadamente.

Quando se trata da saúde indígena, desde a criação da FUNAI, em 1967, diferentes órgãos governamentais e instituições foram responsáveis pelo atendimento aos índios. Em 1999, foi criado o Subsistema de Atenção à Saúde Indígena dentro do SUS e, a partir de uma política de descentralização do atendimento, a ação direta do Estado foi reduzida, e foram implementados 34 Distritos Sanitários Indígenas (DSEIs), delimitados a partir de critérios epidemiológicos, geográficos e etnográficos.

O subsistema de saúde indígena era, até 2010, gerido pela Fundação Nacional de Saúde (FUNASA). Contudo, a partir de uma demanda do movimento indígena, desde essa data, a gestão da saúde indígena passou às mãos de uma secretaria específica, vinculada diretamente ao Ministério da Saúde, a Secretaria Especial de Saúde Indígena (SESAI).

Na SESAI há uma área técnica de saúde mental, a qual foi constituída por uma equipe de profissionais, entre eles, psicólogos, assistentes sociais, antropólogos e outros. Essa interdisciplinaridade ocorre tanto na sede quanto nos DSEls, os quais planejam ações em saúde mental. Diversas frentes, baseadas em variadas metodologias, são elaboradas, de acordo com o contexto e a urgência de cada demanda. Levando em consideração a complexidade inerente ao tema, as práticas institucionais da SESAI em saúde mental ainda estão em gradativa e constante construção.

O tema saúde das populações indígenas, incluindo o subtema da saúde mental, passou a ter o olhar mais atento do Estado no fim da década de 1990 (Langdon \& Garnelo, 2004) quando questões como o uso excessivo de álcool e substâncias psicoativas, bem como grande número de mortes por suicídio ganharam visibilidade por meio da mídia e pesquisas acadêmicas. Mas só em 2007 entrou em vigor a Portaria no 2759 (Ministério da Saúde, 2007), a qual estabelece diretrizes gerais para a Política de Atenção Integral à Saúde Mental das Populações Indígenas.

Exemplo recente da situação de vulnerabilidade das populações indígenas são os novos dados do Mapa da Violência de 2014 (Cebela, 2014), que trazem como primeira posição do ranking em suicídios o município de São Gabriel da Cachoeira, no estado do Amazonas, com população majoritariamente indígena. A pesquisa revela que, entre 2008 e 2012, a taxa de suicídios na cidade foi de 50 casos por 100 mil habitantes, dez vezes maior do que a média brasileira. Entre os que se mataram, 93\% eram índios. Além de São Gabriel da Cachoeira, outras cidades com presença massiva de populações indígenas estão nas primeiras posições da lista dos suicídios, como São Paulo de Olivença e Tabatinga, no Amazonas, Amambai, Dourados e Paranhos, no Mato Grosso do Sul. Outros dados que ratificam esse quadro estão no relatório do Conselho Indigenista Missionário (CIMI, 2013), lançado em Brasília em 17/07/2014 na sede da Conferência Nacional dos Bispos do Brasil (CNBB), que reúne dados de violência sofrida por povos indígenas de todo o país, cujo resultado aponta para 73 suicídios cometidos por indígenas no Mato Grosso do Sul no ano de 2013. O número é o maior dos últimos 28 anos.

Diante desse cenário, é de suma importância compreender como tais temas - suicídio, alcoolização e outros - relacionados à saúde mental e à psicologia, têm sido contemplados e discutidos nas produções acadêmicas brasileiras referentes a povos indígenas. O presente trabalho teve, assim, por objetivo realizar um levantamento bibliográfico de artigos publicados nos últimos 13 anos (de 1999 a 2012) nas principais plataformas eletrônicas científicas brasileiras. O propósito geral foi investigar, mapear e delinear o que foi e tem sido pesquisado no Brasil sobre o tema saúde mental em contextos indígenas.

\section{Metodologia}

Para mapear a produção científica sobre saúde mental e populações indígenas no Brasil entre os anos de 1999 e 2012, foi realizado um levantamento bibliográfico de artigos publicados em plataformas virtuais conhecidas e consolidadas no meio acadêmico, sendo elas: SciELO (scielo.org.br) e Biblioteca Virtual em Saúde Psicologia Brasil - BVS-Psi (bvs-psi.org.br).

A busca de artigos científicos foi subdividido em duas partes: na primeira a busca se deu numa plataforma pluridisciplinar e na segunda numa plataforma restrita à área de psicologia. Como o campo da saúde mental é um campo essencialmente interdisciplinar, que conta com a participação de várias áreas do conhecimento e profissionais diferentes, como prevê as diretrizes da política de saúde mental no Brasil (Ministério da Saúde, 2004), o levantamento de artigos foi inicialmente realizado em uma 
plataforma pluridisciplinar (SciELO). Foi utilizado apenas o SciELO Brasil, visto que o objetivo deste trabalho era fazer um levantamento especificamente das produções brasileiras acerca do tema, independentemente da língua na qual os artigos foram escritos.

A plataforma SciELO é uma biblioteca eletrônica que abrange uma coleção de periódicos científicos e disponibiliza, gratuitamente, os textos completos de artigos de inúmeras revistas científicas. Dentro das suas ferramentas de busca, é possível selecionar uma pesquisa restrita ao SciELO Brasil, que está vinculada somente a periódicos brasileiros.

Por outro lado, considerando que a psicologia tem assumido um papel de extrema relevância e representatividade dentro das políticas e das ações em saúde mental no Brasil (Cantele, Arpini, \& Roso, 2012) e que este trabalho tem no seu referencial o olhar da psicologia, foi escolhida outra plataforma cujo recorte é exclusivo da área de psicologia (BVS-Psi). Isso possibilita observar como a psicologia brasileira tem tratado a temática da saúde mental em contexto indígena nas suas produções acadêmicas. A BVS-Psi divulga trabalhos de inúmeras bases bibliográficas, como Index Psi técnico-científicas, Index Psi divulgação cientifica, PePsic, Lilacs.

O levantamento foi realizado em dois períodos: de agosto/2012 a outubro/2012, foi explorada a plataforma SciELO Brasil. Foram abrangidos os artigos publicados de 1999 até o final de outubro de 2012. O segundo período de busca se deu de abril/2013 a maio/2013, no qual foram pesquisadas as bases bibliográficas da plataforma Biblioteca Virtual em Saúde Psicologia Brasil (Index Psi técnico científicas, Index Psi divulgação cientifica, PePsic e Lilacs). Foram levantados os artigos publicados entre os anos de 1999 a 2012 (completo).

Foram utilizados três grupos de descritores e correlatos, gerando um total de 62 combinações de busca. No primeiro grupo de descritores foi utilizado o descritor saúde mental e 26 correlatos. Foram eles: saúde, mental, doença mental, transtorno mental, adoecimento psíquico, sofrimento psíquico, psíquico, psicologia, psiquiatria, psicopatologia, suicídio, Caps, álcool, alcoolismo, cirrose, depressão, transtorno de ansiedade, esquizofrenia, psicose, substâncias psicoativas, drogas, violência, manual diagnóstico e estatístico de transtornos mentais, DSM, classificação internacional de doenças e CID.

No segundo grupo de descritores foram utilizados os termos índio e indígena, que foram buscados isoladamente e também combinados a todos os descritores do primeiro grupo.
No terceiro grupo foi utilizado o termo etno seguido de termos vinculados a áreas da saúde mental. Foram eles: etnopsicologia, etnopsiquiatria, psicologia etnologia, etnologia psíquica, etnologia psíquico, etnologia psicológica. As buscas deste terceiro grupo foram feitas sem a combinação com descritores do primeiro e/ ou segundo grupo.

A combinação entre os descritores do primeiro e segundo grupos, adicionada aos descritores do terceiro grupo, resultou em 62 buscas, realizadas identicamente e na mesma ordem em cada plataforma.

Foram encontrados, inicialmente, 406 artigos nas plataformas SciELO Brasil e 5104 na BVS-PSI. A seleção dos trabalhos relevantes à pesquisa foi feita a partir da leitura dos resumos de cada artigo encontrado na busca. Aqueles artigos que não se referiam à saúde mental indígena, ou se referiam apenas a questões de saúde mental ou apenas a populações indígenas sem vínculo com a saúde mental, foram descartados. Foram descartados também artigos que não tratassem de populações indígenas brasileiras. E, por último, as aparições repetidas. Por "repetidos" consideramos aqueles artigos que apareceram em mais de uma base bibliográfica. Foi considerada apenas sua primeira aparição.

Na plataforma SciELO Brasil, sobraram apenas 25 artigos dentro do tema, porém com 16 repetições, restaram apenas oito ao final. Nas bases bibliográficas da plataforma BVS-Psi Brasil, encontramos os seguintes resultados: na plataforma Index Psi Técnico Científicas 70 artigos, restando somente três referentes ao tema pesquisado; na plataforma Index Psi Divulgação Científica, nenhum artigo foi encontrado; na plataforma PePsic foram encontrados 52 artigos, sendo apenas cinco relacionados ao tema (porém todos repetidos de outras plataformas, sendo portanto descartados); na plataforma Lilacs, cuja base de dados é a maior dentre as plataformas, foram encontrados 4982 artigos, cujos resumos foram todos lidos, para se chegar ao número de 94 artigos relacionados ao tema. Contudo, após a exclusão dos repetidos, e de acordo com os critérios de seleção utilizados, apenas três artigos foram selecionados.

Abaixo, segue uma tabela-resumo do levantamento realizado (Tabela 1) que mostra o número total de artigos encontrados em cada plataforma, seguido do número de artigos afinados ao tema, e por fim, o número final de artigos considerados, após a exclusão dos repetidos.

Ao todo, restaram 14 artigos sendo oito da plataforma pluridisciplinar e seis das plataformas com o recorte da Psicologia. 
Saúde mental em contextos indígenas

Tabela 1. Processo de Levantamento e Seleção dos Artigos.

\begin{tabular}{|c|c|c|c|c|c|c|}
\hline & \multirow{2}{*}{$\begin{array}{c}\begin{array}{c}\text { Plataforma } \\
\text { pluridisciplinar }\end{array} \\
\text { SciELO Brasil }\end{array}$} & \multicolumn{5}{|c|}{ Plataformas que contemplam publicações da área de psicologia } \\
\hline & & $\begin{array}{c}\text { Index Psi } \\
\text { Técnico Científicas }\end{array}$ & $\begin{array}{c}\text { Index Psi } \\
\text { Divulgação Científica }\end{array}$ & PePsic & Lilacs & Total \\
\hline Número de artigos encontrados & 406 & 70 & 0 & 52 & 4982 & 5510 \\
\hline Artigos dentro do tema & 25 & 14 & 0 & 5 & 94 & 138 \\
\hline $\begin{array}{l}\text { Total de artigos selecionados } \\
\text { (excluídas as repetições) }\end{array}$ & 8 & 3 & 0 & 0 & 3 & 14 \\
\hline
\end{tabular}

Foi realizada uma leitura minuciosa desses artigos, a partir dos quais foram levantados os seguintes dados: ano de publicação; etnia do grupo pesquisado; país e Estado/região onde a pesquisa foi realizada; sexo dos participantes da pesquisa (feminino, masculino, ambos ou não especificado); faixa etária dos participantes da pesquisa (criança, jovem/adulto, idoso, todos ou não especificado); tipo de trabalho (teórico ou empírico); tema/objeto do artigo; problematização (ou não) do conceito de saúde mental (e, em caso positivo, como foi realizada); problematização (ou não) do conceito de índio (e, em caso positivo, como foi realizada); utilização (ou não) de critérios do DSM; consideração (ou não) de questões psíquicas/subjetivas/psicológicas no estudo; participação (ou não) de psicólogos no estudo. Segue a tabela com o resumo dos dados levantados (Tabela 2).

\section{Resultados e discussão}

A distribuição dos 14 artigos brasileiros que tocam o tema saúde mental em contextos indígenas brasileiros, publicados entre os anos de 1999 e 2012, se deu na seguinte frequência ao longo do tempo: dois artigos em 2006; quatro em 2007; dois em 2010; três em 2011; e três em 2012.

É possível observar que a publicação de artigos relativos à saúde mental em contextos indígenas começou a aparecer somente em 2006, sendo que os anos de 2007, 2011 e 2012 foram os de maior destaque em publicações acerca do tema. Em 2007 ocorreu a I Conferência Nacional de Saúde Mental Indígena, promovida pela Fundação Nacional de Saúde (FUNASA). Além disso, foi por meio desse evento que as bases da Portaria $n^{-}$ 2759 do Ministério da Saúde foram elaboradas, estabelecendo as Diretrizes Gerais para a Política de Atenção Integral à Saúde Mental das Populações Indígenas. É neste momento, com a implantação de uma política de saúde para populações indígenas, que o tema saúde mental em contextos indígenas começou a ganhar visibilidade no Brasil.
Em relação às etnias pesquisadas, 50\% dos artigos, ou seja, sete artigos, (Bonfim, 2011; Guimarães \& Grubits, 2007; Souza, Deslandes, \& Garnelo, 2010; Souza \& Garnelo, 2006, 2007; Souza \& Orellana, 2012; Souza, Schweickardt, \& Garnelo, 2007) não cita a etnia sobre a qual realizaram a pesquisa. Isso acontece por alguns motivos: ou o artigo se refere a indígenas de determinada região - por exemplo, Alto Rio Negro - e não se especifica a(s) etnia(s) envolvidas, ou porque se trata de um artigo teórico referente aos indígenas brasileiros, de maneira geral. Os outros $50 \%$ trataram das seguintes etnias: Karajá (1), Krahô (1), Karitiana (1), Potiguara (1), Guarani (3). Observa-se que a etnia mais pesquisada é a Guarani, dado que reflete a maior visibilidade que esse grupo tem tido na mídia e nas organizações pró-indígenas. Diante da condição de extrema vulnerabilidade em que se encontram, cada vez mais confinados em pequenos territórios, pressionados pelo agronegócio, convivendo com altos índices de suicídio e violência, os índios Guarani têm despertado também um olhar mais consistente de pesquisadores devido à condição de extremo desamparo a que estão submetidos.

Em relação à distribuição dos artigos de acordo com a região onde a pesquisa foi realizada obtivemos os resultados a seguir. Na Região Norte, encontramos sete artigos, sendo três referentes ao Estado do Amazonas, dois específicos da Região do Alto Rio Negro, um referente a Rondônia e um ao Tocantins. Na região Nordeste, temos um artigo referente ao Estado da Paraíba. No Centro Oeste temos um artigo relativo ao Estado Mato Grosso do Sul. No Sudeste temos um artigo concernente ao Estado de São Paulo e na Região Sul, um artigo relativo ao estado de Santa Catarina. Os três artigos restantes não citam nenhuma região específica por discutirem questões em nível nacional ou por serem estudos teóricos sem referências a uma região específica. De acordo com esses dados, é possível observar que a Região Norte, principalmente a região amazônica, tem sido a região com maior número de publicações acerca do tema saúde mental no contexto indígena (sete artigos, ou seja, metade dos artigos encontrados). 
Tabela 2. Comparação dos Artigos Encontrados no Levantamento Bibliográfico.

\begin{tabular}{|c|c|c|c|c|}
\hline $\begin{array}{l}\text { Autores/Ano de } \\
\text { publicação }\end{array}$ & Título do artigo/Tipo de trabalho & $\begin{array}{l}\text { Etnia do } \\
\text { grupo/Região }\end{array}$ & $\begin{array}{l}\text { Reflexões epistemológicas (conceito de } \\
\text { saúde mental e índio; Critérios do DSM) }\end{array}$ & $\begin{array}{c}\text { Presença de psicólogos } \\
\text { na pesquisa }\end{array}$ \\
\hline $\begin{array}{l}\text { Andrade, V. M. } \\
\text { \& Bueno, O. F. A. } \\
(2007)\end{array}$ & $\begin{array}{l}\text { Neuropsicologia transcultural: grupo } \\
\text { indígena Guarani/Trabalho de campo }\end{array}$ & Guarani/SP & $\begin{array}{l}\text { Não problematiza o conceito de saúde } \\
\text { mental nem o conceito de índio. Baseia-se } \\
\text { nos critérios do DSM. }\end{array}$ & $\operatorname{Sim}$ \\
\hline $\begin{array}{l}\text { Azevêdo, P.V.B, } \\
\text { Caixeta, L., } \\
\text { Andrade, L. H. S. \& } \\
\text { Bordin, I. A. (2010). }\end{array}$ & $\begin{array}{l}\text { Attention deficit/hyperactivity disorder } \\
\text { symptoms in indigenous children from the } \\
\text { Brazilian Amazon/Trabalho de campo }\end{array}$ & $\begin{array}{l}\text { Karajá/ } \\
\text { Amazônia }\end{array}$ & $\begin{array}{l}\text { Não problematiza o conceito de saúde } \\
\text { mental nem o conceito de índio. Baseia-se } \\
\text { nos critérios do DSM. }\end{array}$ & Não \\
\hline Bonfim, T. E. (2011) & $\begin{array}{l}\text { Avaliação psicológica e saúde mental: } \\
\text { aplicações da psicologia clínica em } \\
\text { comunidades indígenas/Trabalho teórico }\end{array}$ & $\begin{array}{l}\text { Não apresenta } \\
\text { região e etnia }\end{array}$ & $\begin{array}{l}\text { Não problematiza o conceito de saúde } \\
\text { mental nem o conceito de índio. Baseia-se } \\
\text { nos critérios do DSM. }\end{array}$ & $\operatorname{Sim}$ \\
\hline $\begin{array}{l}\text { Diehl, E. E. \& } \\
\text { Grassi, F. (2010) }\end{array}$ & $\begin{array}{l}\text { Uso de medicamentos em uma aldeia } \\
\text { Guarani do litoral de Santa Catarina, } \\
\text { Brasil/Trabalho de campo }\end{array}$ & Guarani/SC & $\begin{array}{l}\text { Não problematiza o conceito de sáude } \\
\text { mental nem o conceito de índio. Baseia-se } \\
\text { nos critérios do DSM. }\end{array}$ & Não \\
\hline $\begin{array}{l}\text { Grubits, S. Freire, } \\
\text { H. B. G. \& Noriega, } \\
\text { J. A. V. (2011) }\end{array}$ & $\begin{array}{l}\text { Suicídios de jovens Guarani/Kaiowá de } \\
\text { Mato Grosso do Sul, Brasil/Trabalho de } \\
\text { campo }\end{array}$ & $\begin{array}{l}\text { Guarani } \\
\text { Kaiowá/MS }\end{array}$ & $\begin{array}{l}\text { Não problematiza o conceito de saúde } \\
\text { mental nem o conceito de índio. Não se } \\
\text { baseia nos critérios do DSM. }\end{array}$ & Sim \\
\hline $\begin{array}{l}\text { Guimarães, L. A. \& } \\
\text { Grubits, S. (2007) }\end{array}$ & $\begin{array}{l}\text { Alcoolismo e violência em etnias } \\
\text { indígenas: uma visão crítica da situação } \\
\text { brasileira/Trabalho teórico }\end{array}$ & $\begin{array}{l}\text { Não apresenta } \\
\text { região e etnia }\end{array}$ & $\begin{array}{l}\text { Não problematiza o conceito de saúde } \\
\text { mental nem o conceito de índio. Não se } \\
\text { baseia nos critérios do DSM. }\end{array}$ & $\operatorname{Sim}$ \\
\hline $\begin{array}{l}\text { Melo, J. R. F.; Ma- } \\
\text { ciel, S. C.; Oliveira, } \\
\text { R. C. C. De \& Silva, } \\
\text { A. O. (2011). }\end{array}$ & $\begin{array}{l}\text { Implicações do uso do álcool na } \\
\text { comunidade indígena Potiguara/Trabalho } \\
\text { de campo }\end{array}$ & Potiguara/PB & $\begin{array}{l}\text { Não problematiza o conceito de saúde } \\
\text { mental nem o conceito de índio. Não se } \\
\text { baseia nos critérios do DSM. }\end{array}$ & $\operatorname{Sim}$ \\
\hline $\begin{array}{l}\text { Rodrigues, E. \& } \\
\text { Carlini, E. A. (2006). }\end{array}$ & $\begin{array}{l}\text { Plantas com possíveis ações } \\
\text { psicoativas utilizadas pelos índios Krahô, } \\
\text { Brasil/Trabalho de campo }\end{array}$ & Krahô/TO & $\begin{array}{l}\text { Não problematiza o conceito de saúde } \\
\text { mental nem o conceito de índio. Baseia-se } \\
\text { nos critérios do DSM. }\end{array}$ & $\operatorname{Sim}$ \\
\hline $\begin{array}{l}\text { Souza, M. L. P. \& } \\
\text { Garnelo, L. (2006). }\end{array}$ & $\begin{array}{l}\text { Desconstruindo o alcoolismo: notas a partir } \\
\text { da construção do objeto de pesquisa no } \\
\text { contexto indígena/Trabalho teórico }\end{array}$ & $\begin{array}{l}\text { Não apresenta } \\
\text { etnia/Alto Rio } \\
\text { Negro (AM) }\end{array}$ & $\begin{array}{l}\text { Não problematiza o conceito de saúde } \\
\text { mental nem o conceito de índio. Não se } \\
\text { baseia nos critérios do DSM. }\end{array}$ & Não \\
\hline $\begin{array}{l}\text { Souza, M. L. P., } \\
\text { Schweickardt, J. } \\
\text { C. \& Garnelo, L. } \\
\text { (2007). }\end{array}$ & $\begin{array}{l}\text { O processo de alcoolização em populações } \\
\text { indígenas do Alto Rio Negro e as limitações } \\
\text { do Cage como instrumento de screening } \\
\text { para dependência ao álcool/Trabalho de } \\
\text { campo }\end{array}$ & $\begin{array}{l}\text { Não apresenta } \\
\text { etnia/Alto Rio } \\
\text { Negro (AM) }\end{array}$ & $\begin{array}{l}\text { Não problematiza o conceito de saúde } \\
\text { mental nem o conceito de índio. Não se } \\
\text { baseia nos critérios do DSM. }\end{array}$ & Não \\
\hline $\begin{array}{l}\text { Souza, M. L. P. \& } \\
\text { Garnelo, L. (2007). }\end{array}$ & $\begin{array}{l}\text { Quando, como e o que se bebe: o processo } \\
\text { de alcoolização entre populações indígenas } \\
\text { do alto rio negro, Brasil/Trabalho teórico }\end{array}$ & $\begin{array}{l}\text { Não apresenta } \\
\text { etnia/Alto Rio } \\
\text { Negro (AM) }\end{array}$ & $\begin{array}{l}\text { Não problematiza o conceito de saúde } \\
\text { mental nem o conceito de índio. Não se } \\
\text { baseia nos critérios do DSM. }\end{array}$ & Não \\
\hline $\begin{array}{l}\text { Souza, M. L. P., } \\
\text { Deslandes, S. F. \& } \\
\text { Garnelo, L. (2010). }\end{array}$ & $\begin{array}{l}\text { Modos de vida e modos de beber de } \\
\text { jovens indígenas em um contexto de } \\
\text { transformações/Trabalho de campo }\end{array}$ & $\begin{array}{l}\text { Não apresenta } \\
\text { etnia/Alto Rio } \\
\text { Negro (AM) }\end{array}$ & $\begin{array}{l}\text { Não problematiza o conceito de saúde } \\
\text { mental nem o conceito de índio. Não se } \\
\text { baseia nos critérios do DSM. }\end{array}$ & Não \\
\hline $\begin{array}{l}\text { Souza, M. L. P. \& } \\
\text { Orellana, J. D. Y. } \\
\text { (2012). }\end{array}$ & $\begin{array}{l}\text { Suicide mortality in São Gabriel da } \\
\text { Cachoeira, a predominantly indigenous } \\
\text { Brazilian municipality/Trabalho teórico }\end{array}$ & $\begin{array}{l}\text { Não apresenta } \\
\text { etnia/São } \\
\text { Gabriel da } \\
\text { Cachoeira (AM) }\end{array}$ & $\begin{array}{l}\text { Não problematiza o conceito de saúde } \\
\text { mental nem o conceito de índio. Se baseia } \\
\text { nos critérios do DSM. }\end{array}$ & Não \\
\hline $\begin{array}{l}\text { Vianna, J. J. Cedaro, } \\
\text { J. J. \& Ott, A. M. } \\
\text { (2012). }\end{array}$ & $\begin{array}{l}\text { Aspectos psicológicos na utilização } \\
\text { de bebidas alcoólicas entre os } \\
\text { Karitiana/Trabalho de campo }\end{array}$ & Karitiana/RO & $\begin{array}{l}\text { Problematiza o conceito de saúde mental } \\
\text { e o conceito de índio. Não se baseia nos } \\
\text { critérios do DSM. }\end{array}$ & Sim \\
\hline
\end{tabular}

Em relação à característica sexo, os artigos apareceram da seguinte maneira: um artigo trata exclusivamente dos homens, sete se referem a ambos os sexos, seis não citam um público específico e nenhum se dedica exclusivamente às mulheres. Levando em consideração o processo de contato pelo qual passou e tem passado alguns destes povos, e os problemas levantados pelas diferenças culturais, dentre elas os aspectos daquilo que em nossa cultura se denomina gênero, pode-se apontar a falta de discussões acerca destes aspectos e saúde mental em contextos indígenas. 
Na característica faixa etária, os resultados foram: dois artigos relacionados a crianças, dois relacionados a jovens/adultos, 0 relacionados ao idoso, cinco artigos abrangendo todas as idades e cinco artigos que não fizeram referência a faixa etária.

Pode-se pensar em algumas hipóteses para estes dados: os estudos em saúde mental em contextos indígenas ainda são tão incipientes que não permitem um recorte desse tipo, ficando restritos a discussões generalistas em relação à faixa etária. Da mesma forma, pode-se pensar que a categoria faixa etária (da forma marcada como a compreendemos) diz respeito a uma elaboração não indígena que não encontra muito sentido nos contextos indígenas, e por isso não é abordada.

Dos 14 artigos, observamos que a minoria é teórica - cinco artigos - (Bonfim, 2011; Guimarães \& Grubits, 2007; Souza \& Garnelo, 2006; Souza \& Garnelo, 2007; Souza \& Orellana, 2012) em relação aos trabalhos com pesquisa de campo - nove artigos - (Andrade \& Bueno, 2007; Azevêdo, Caixeta, Andrade, \& Bordin, 2010; Diehl \& Grassi, 2010; Grubits \& Noriega, 2011; Melo, Maciel, Oliveira, \& Silva, 2011; Rodrigues \& Carlini, 2006; Souza, et al., 2010; Souza et al., 2007; Vianna, Cedaro, \& Ott, 2012). Por um lado, esse resultado reflete a urgência das demandas indígenas que, muitas vezes, têm interesse que profissionais estejam em campo. Porém, a partir da análise crítica dos artigos, observou-se a necessidade de maior aprofundamento e questionamento teórico dos pressupostos epistemológicos das pesquisas voltadas para o tema em foco. Muitos outros países, tais como Canadá, França, Portugal, Estados Unidos, Itália e Reino Unido, têm desenvolvido uma ampla discussão teórica em relação à saúde mental e diversidade cultural (Lechner, 2009). Nesses países, por meio de algumas universidades $^{1}$, a temática sofrimento/aflição tem sido debatida a partir das contribuições da psiquiatria transcultural e da etnopsiquiatria, cujas reflexões se propõem a problematizar critérios diagnósticos fixos descolados da vivência cultural e da valoração que cada grupo tem acerca do seu adoecimento.

Levando em conta a baixa produção teórica acadêmica sobre o tema, torna-se fundamental a criação de políticas públicas de incentivo, para que seja possível não apenas o estudo de campo sobre e com os povos específicos que vivem no Brasil, mas também que haja um impacto do reconhecimento destas diversidades no arcabouço epistemológico que possuímos para pensar a saúde mental. Ou seja, que sejam criadas condições para se (re)pensar os conceitos de saúde mental e indígena, problematizando-os em uma constante conversação com as especificidades dos trabalhos de campo realizados.

Apenas 50\% dos artigos (Andrade \& Bueno, 2007; Bonfim, 2011; Guimarães \& Grubits, 2007; Grubits \& Noriega, 2011; Melo et al., 2011; Rodrigues \& Carlini, 2006; Vianna et al., 2012) contaram com a presença de psicólogos como pesquisadores. Essa característica foi observada, visto que um dos objetivos deste trabalho é constatar como tem sido a produção cientifica da área de psicologia quando se trata de questões indígenas. $\mathrm{O}$ resultado indica que metade dos artigos contou com pesquisadores psicólogos junto a pesquisadores de outras áreas da saúde mental, como antropólogos, psiquiatras e enfermeiros. A outra metade dos artigos encontrados foi fruto de pesquisas de outras áreas (psiquiatria e antropologia) sem envolvimento de psicólogos.

Esse dado reflete a pouca adesão do profissional psicólogo diante das demandas de saúde mental nas populações indígenas. Mesmo a psicologia sendo um campo de extrema importância no conjunto de disciplinas que compõem a saúde mental, os profissionais psicólogos ainda não se sobressaem como pesquisadores dessa área. Isto aponta para uma falha na formação acadêmica desse profissional, diante de demandas relativas à diversidade étnica e cultural. Os currículos universitários raramente possuem disciplinas que discutam o tema. Levando em consideração a diversidade étnica no Brasil e as demandas crescentes, nos últimos anos, pelo olhar da saúde mental em contextos indígenas, é indispensável que haja inclusão destes debates nos cursos de graduação em Psicologia, bem como sensibilização dos profissionais já formados e formação específica para aqueles que queiram trabalhar neste campo (CRPSP, 2010; Vitale \& Grubits, 2009).

No que diz respeito às questões psíquicas/subjetivas/psicológicas, observa-se que a minoria dos artigos, apenas cinco (Andrade \& Bueno, 2007; Bonfim, 2011; Grubits \& Noriega, 2011; Guimarães \& Grubits, 2007; Vianna et al., 2012), citam a influência das questões subjetivas nas suas discussões. Estes cinco artigos foram encontrados nas bases bibliográficas da BVS-Psi. Cabe observar que as próprias categorias de saúde mental e aspectos psíquicos/subjetivos/psicológicos são construções que partem de um modelo explicativo ocidental que pode ou não encontrar consonância com os modelos de explicações indígenas (Stock, 2010).

Em relação ao número de artigos que problematizam o conceito de saúde mental, encontramos apenas um artigo (Vianna et al., 2012) que o faz, enquanto os 
demais sequer o citam. Esse dado aponta como o conceito de saúde mental é tomado de maneira reificada na grande maioria das publicações. Observou-se que a maioria dos estudos tratou as questões de saúde mental como algo dado, fixo, e não como uma construção localizada culturalmente para uma resposta a demandas sociais. Ou seja, há uma invisibilidade dos aspectos teóricos e sociais da definição da loucura em nossa própria cultura (Foucault, 1973).

Além disso, como afirma Kleinman (1978), Littlewood (1990), Martinez-Hernáez (2000), Kirmayer (2006), Esperanza (2011) e outros autores que problematizam as categorias psiquiátricas, a partir do momento em que se passa a explicar o mental a partir de um aparato lógico e semiológico importado de um saber organicista, tende-se a se afirmar que tudo aquilo referente ao mental também tenha seu correlato orgânico, palpável, explícito, e despreze outras influências, como momento histórico, condições sociais, vivências culturais, entre outros.

O artigo mostra como o uso da categoria saúde mental pode ser problemático, já que aspectos que facilmente seriam remetidos à área de saúde mental em nossa sociedade, como dependência de álcool e drogas, suicídio e uso de psicofármacos, não são tão evidentes em populações indígenas, exigindo cuidados éticos e culturais (Vianna et al., 2012). Contudo, mesmo que este estudo aponte para a problematização da reificação de conceitos ocidentais, ele também parte de pressupostos ancorados em categorias ocidentais para mapear o contexto da saúde mental indígena brasileira, visto que não há possibilidade de pensar essas questões nos despindo de categorias.

No que diz respeito ao número de artigos que problematizam o conceito de índio e indígena, temos o mesmo cenário anterior. Apenas um artigo discute tal conceito, o mesmo que problematizou o conceito de saúde mental (Vianna et al., 2012), mostrando como, na maioria das vezes, o conceito de indígena é visto de maneira homogênea, desconsiderando suas especificidades enquanto povos diversos e heterogêneos. Segundo Cunha (1986), o termo indígena vem do latim relacionado com o grego endogenés, que significa nascido em casa, referindo-se àquele que já se encontrava em determinado território antes da chegada de outrem. A ideia de povos indígenas nos induz, portanto, a uma imagem de coletividade homogênea, reduzindo a multiplicidade de grupos étnicos que habitam o país desde muito antes da colonização europeia. José (2010) afirma que tratar a diversidade das populações indígenas no Brasil reduzindo-as ao termo "índios" significa desprezar inúmeras concepções de realidade e vivências, formas de expressar os sofrimentos/aflições, categorizá-los, compreendê-los e tratá-los.

Em relação ao número de artigos que se utilizam (explicitamente ou implicitamente) dos critérios do DSM, observa-se certo equilíbrio entre aqueles que os usam para embasar suas discussões - seis artigos - (Andrade \& Bueno, 2007; Azevêdo et al., 2010; Bonfim, 2011; Diehl \& Grassi, 2010; Rodrigues \& Carlini, 2006; Souza $\&$ Orellana, 2012) e aqueles que mostram um esforço multidisciplinar para orientar seus posicionamentos oito artigos (Guimarães \& Grubits, 2007; Melo et al., 2011; Souza \& Garnelo, 2006; Souza \& Garnelo, 2007; Souza et al., 2010; Souza, Grubits, \& Noriega, 2011; Souza et al., 2007; Vianna et al., 2012), considerando a influência e dinâmica cultural para explicações dos fenômenos. Estes artigos, apesar de recorrerem a outros sistemas explicativos para discorrerem sobre aspectos vinculados à saúde mental em contextos indígenas, não problematizam em si o conceito de saúde mental, com exceção de um (Vianna et al., 2012), como se esta fosse uma instância preexistente, "ateórica", sem necessidade de contextualização.

O uso indiscriminado e sem reflexão dos critérios do DSM diante do sofrimento psíquico indígena traz à tona a discussão, proposta por vários autores, ao longo de várias décadas, como Yap (1951), Kleinman (1991), Littlewood (1990), Martinez-Hernáez (2000), Kirmayer (2009), Lechner (2009), Neto e Calazans (2012), Jerusalinski e Fendrik (2011). Eles mostram a importância de se problematizarem categorias advindas de modelos explicativos ocidentais que não encontram ressonância em modelos explicativos encontrados em outros contextos culturais. Além disso, apontam as limitações da importação de uma lógica semiológica indicial, característica do campo da medicina, para a compreensão do campo da psicopatologia, na qual os modos de expressão do sofrimento/aflição são mediados pela cultura e pelo processo de semiosis, ou seja, são marcados pela presença de sintomas simbólicos (Hernáez, 2000; Martins, 2003).

Em relação à distribuição dos artigos de acordo com o tema abordado por cada um, encontramos: dois sobre suicídio (Grubits \& Noriega, 2011; Souza \& Orellana, 2012), sete abordam o uso do álcool (Guimarães \& Grubits, 2007; Melo et al., 2011; Souza \& Garnelo, 2006, 2007; Souza et al., 2010; Souza et al., 2007; Vianna et al., 2012), um trata do transtorno do déficit de atenção e 
hiperatividade (TDAH) (Azevêdo et al., 2010), dois discutem tipos de avaliação psicológica (Andrade \& Bueno, 2007; Bonfim, 2011) e dois abordam o uso de substâncias psicoativas dentro de aldeias, sendo 1 sobre medicamentos (Diehl \& Grassi, 2010) e outro sobre plantas Krahô (Rodrigues \&Carlini, 2006).

No primeiro tema, suicídio, foram encontrados dois artigos. O primeiro deles (Souza \& Orellana, 2012) visa descrever, utilizando os dados do sistema de informação do SUS, as características e as taxas brutas de mortalidade por suicídio no período de 2000 a 2007, em São Gabriel da Cachoeira, no Amazonas, estado onde há maior número de indígenas autodeclarados. O estudo mapeou que, durante o período investigado, $97,7 \%$ dos suicídios registrados ocorreram entre indígenas (a maioria homens solteiros, por enforcamento) e concluiu que os contextos indígenas no Brasil apresentam um perfil de suicídios bem específico e discrepante do restante dos segmentos sociais. $\mathrm{O}$ artigo apresenta um foco exclusivamente estatístico e, como na maioria dos artigos levantados, não discute o conceito de saúde mental, nem o conceito de indígena, utilizando-se, sem questionamentos, dos critérios do DSM.

O segundo deles (Grubits \& Noriega, 2011) tenta compreender alguns motivos que levam jovens Guarani Kaiowá no Estado do Mato Grosso do Sul a cometerem suicídio em um índice bem maior se comparado à sociedade não indígena. $\mathrm{O}$ artigo não discute o conceito especifico de saúde mental nem o conceito de indígena, e não utiliza os critérios do DSM para pensar o suicídio entre os Guarani, valendo-se de critérios culturais e históricos para pensar o fenômeno. O artigo é um dos poucos que trazem a influência de questões psíquicas/ subjetivas/psicológicas nas suas discussões, talvez por serem da área de psicologia e saúde mental.

Dentro do tema uso de álcool, observamos o maior número de artigos encontrados (sete). Dado muito relevante, pois indica claramente um dos maiores problemas que os povos indígenas têm enfrentado nas últimas décadas. Trata-se de uma área que claramente necessita de incentivos de políticas públicas para a realização de pesquisas que contribuam para a discussão do tema.

O primeiro artigo (Vianna et al., 2012) busca analisar os problemas relacionados ao uso do álcool entre os Karitiana (RO), visando compreender os modos de se utilizar a bebida e observando os aspectos psicológicos envolvidos nesse processo. $\mathrm{O}$ artigo trabalha em uma perspectiva multidisciplinar e tenta pensar possibilidades de atuação do psicólogo entre populações indígenas, considerando, assim, a influência de aspectos psíquicos no processo de alcoolização. Este é o único artigo do levantamento que problematiza o conceito saúde mental, discutindo de maneira crítica a equivalência indiscriminada de conceitos entre culturas diferentes. Trata-se, também, do único artigo que problematiza o conceito de indígena, ressaltando a importância de se observar a pluralidade de povos no país e as significativas diferenças entre suas cosmologias.

O segundo artigo (Guimarães \& Grubits, 2007) tenta trazer a relação entre alcoolismo e violência entre povos indígenas do Brasil. O estudo discute a complexidade e as interfaces do alcoolismo, ressaltando a grande influência da vivência cultural no consumo e nos efeitos do álcool. O artigo não problematiza o conceito de alcoolismo, nem de indígena e em nenhum momento cita o termo saúde mental. Nesse sentido, o artigo não se preocupa em questionar a validade relativa dessas categorias para outras culturas, como as diversas etnias presentes no país.

O terceiro artigo (Melo et al., 2011) teve como objetivo a obtenção de dados a respeito do uso/abuso do álcool na população indígena Potiguara (PB), com o intuito de contribuir para um maior conhecimento desta população e auxiliar os órgãos competentes na implantação de serviços de atenção básica à saúde. A amostra foi composta por 55 índios, de ambos os sexos, maiores de 18 anos. Para a coleta de dados utilizou-se a entrevista semiestruturada. Na análise dos dados foi utilizado o software SPSS e a Análise de Conteúdo Temática. Os resultados foram os seguintes: $41,8 \%$ da amostra têm pelo menos um membro da família que faz uso de álcool em idade precoce, estando desvinculado da cultura e de rituais; e $27,3 \%$ se queixa sobre o uso de bebida e afirma que a bebida traz problemas à família. Segundo as autoras, os resultados permitem afirmar que já existe um consumo abusivo entre os Potiguara. Esse artigo, apesar de trazer para a pauta o adoecimento psíquico, não cita nem problematiza o conceito de saúde mental, nem de indígena.

O restante dos artigos que tratam do tema uso de álcool são pesquisas realizadas por, praticamente, os mesmos autores (Souza \& Garnelo, 2006, 2007; Souza et al., 2010; Souza et al., 2007;) e possuem um eixo que se ramifica em torno da ideia da desconstrução da categoria alcoolismo. O primeiro deles (Souza \&Garnelo, 2006) está mais voltado para a desconstrução teórica dessa categoria, com o objetivo de não utilizá-la no sentido do senso comum para que a discriminação dos povos 
indígenas não seja reforçada. O segundo deles (Souza \& Garnelo, 2007), mesmo seguindo o eixo da desconstrução da categoria, trouxe o foco para o processo de alcoolização entre indígenas do Alto Rio Negro (AM), tentando compreender o que, como e quando se bebe, no intuito de entender a interpretação nativa sobre o fenômeno. Já o terceiro (Souza et al., 2007), utilizou-se de um instrumento/questionário entre os índios do Alto Rio Negro com o objetivo de se levantar o processo de alcoolização dessas populações e, a partir daí, desconstruir as noções universalistas do uso de álcool. Por último, o quarto artigo (Souza et al., 2010), a partir de uma pesquisa etnográfica, se focou nas interações entre os atuais modos de vida e de beber de um pequeno grupo de uma populosa aldeia no Alto Rio Negro, para então demonstrar como a categoria alcoolismo carrega em si um viés reducionista para a explicação do fenômeno.

Esses artigos, apesar de não problematizarem o conceito de saúde mental e indígena, possuem um posicionamento mais crítico diante dos critérios reducionistas e universais biomédicos ao se esforçarem na desconstrução da categoria alcoolismo, propondo, no seu lugar, o termo alcoolização. Este termo busca diminuir a carga patológica do uso do álcool e procura considerar as formas de beber em uma perspectiva ontológica/existencial.

Em relação ao tema Transtorno do Déficit de Atenção e Hiperatividade (TDAH), obteve-se um artigo (Azevêdo et al., 2010), o qual se refere a um estudo produzido para investigar a possibilidade de sintomas do TDAH entre crianças Karajá na Amazônia Legal Brasileira, na Ilha do Bananal, e estimar a prevalência dos sintomas do TDAH entre as pessoas de 7-16 anos de idade. Foram entrevistados, por um psiquiatra infantil, 53 pais de crianças das cinco aldeias mais populosas. Como resultado, os pesquisadores observaram que "13 pais se referiram à tríade sintomatológica clássica do TDAH (desatenção, hiperatividade e impulsividade)" (Azevêdo et al., 2010, p. 4) e concluíram que "o TDAH é um construto clinicamente relevante na população indígena Karajá" (Azevêdo et al., 2010, p. 5).

Nesse artigo, o conceito de saúde mental não é sequer mencionado nem problematizado, tampouco o conceito de Transtorno de Déficit de Atenção e Hiperatividade, que é apresentado de maneira reificada, tendo como referência exclusivamente os critérios do DSM, sem qualquer reflexão crítica desses critérios.

No tema Avaliação Psicológica foram encontrados dois artigos. Ambos tentam pensar possibilidades de aplicação de instrumentos psicológicos em populações indígenas, porém com diferentes enfoques. No primeiro deles (Bonfim, 2011), questiona-se quais instrumentos teórico-técnicos um psicólogo clínico poderia utilizar quando busca compreender o fenômeno psicológico em uma relação interétnica. A partir disso, propõe um instrumento - Escala Diagnóstica Adaptativa Operacionalizada (EDAO) - como um instrumento possível, devido sua abrangência, para avaliar indivíduos de grupos culturalmente diversos. A autora fala de saúde psíquica, mas não problematiza esse conceito, tampouco o de saúde mental e indígena.

O segundo artigo (Andrade \& Bueno, 2007) teve o objetivo de investigar a influência da cultura sobre o desempenho cognitivo. Para tal, foram utilizados alguns testes (Desenho com Cubos, Blocos de Corsi, Dígitos e Nomeação de Figuras) em 24 pessoas (12 indígenas e 12 não indígenas (moradores da periferia de São Paulo) da mesma faixa etária e nível educacional. Segundo os autores, os resultados quantitativos não demonstraram diferenças significativas entre os grupos, porém, concluíram que houve uma tendência estatística dos indígenas mostrarem maior domínio das tarefas visuais e motoras, e os não indígenas das tarefas verbais. Dessa forma, o estudo sugere que é possível que o grupo indígena use a cognição de forma mais concreta e intuitiva, em função do estilo peculiar de vida, das habilidades desenvolvidas, associado à baixa escolaridade. Esse artigo utiliza os critérios do DSM e não discute o conceito de saúde mental, tampouco conceitos bastante questionáveis que aparecem com frequência ao longo do texto tais como: indígena, aculturado, cultura e cognição, assumindo-os como "evidentes", ou seja, como se tais conceitos fossem fixos e autoexplicáveis, sem necessidade de contextualização teórica e epistemológica.

No tema Psicoativos, foram encontrados dois artigos, sendo que um deles discute algumas plantas com possíveis ações psicoativas utilizadas pelos índios Krahô (Rodrigues \& Carlini, 2006), e o outro trata do uso de medicamentos em uma aldeia Guarani do litoral de Santa Catarina (Diehl \& Grassi, 2010). O primeiro deles teve por objetivo principal documentar plantas utilizadas pelos índios Krahô (TO) em rituais de cura, principalmente aquelas com potenciais ações psicoativas. Os resultados foram comparados a um levantamento bibliográfico sobre plantas psicoativas utilizadas por outras 25 etnias brasileiras. Por dois anos, foi realizado trabalho de campo utilizando-se métodos da antropologia e botânica. Sete xamãs foram entrevistados e indicaram 98 receitas 
preparadas para 25 usos diferentes, como: "para evitar ficar louco", "estimulante", "para diminuir tremores", "para dormir por mais tempo", "para abrir a cabeça", entre outros. A pesquisa concluiu que a terapêutica utilizada pelos Krahô para combater males psicológicos/ psiquiátricos a partir de plantas é bem complexa e, a partir de novos estudos, podem enriquecer a psiquiatria com novos medicamentos fitoterápicos, que são raros para esse tipo de tratamento. $\mathrm{O}$ artigo não problematiza o conceito de saúde mental, tampouco o que são "males psicológicos" e psiquiátricos para os Krahô, demonstrando pouca reflexão acerca dos problemas relacionados à tradução cultural.

O segundo artigo (Diehl \& Grassi, 2010) investigou o consumo de medicamentos entre os índios Guarani de uma aldeia no litoral de Santa Catarina, a partir da identificação dos medicamentos prescritos e da percepção do uso dos mesmos pelos Guaranis. Foram analisados seis meses de prescrição médica, com um resultado de 458 medicamentos indicados em 236 consultas, sobressaindo-se os medicamentos para tosse, resfriado, diarreia, analgésicos, anti-helmínticos e psicotrópicos. Embora as discussões envolvessem outras referências e critérios além daqueles estabelecidos pelo DSM, o conceito de saúde mental não é discutido, tampouco o conceito de indígena, como na maioria das publicações encontradas.

\section{Conclusão}

Como dito anteriormente, o objetivo do presente artigo foi realizar um levantamento quantitativo e qualitativo de artigos nas principais plataformas científicas brasileiras sobre o tema saúde mental em contextos indígenas.

Antes que se teçam as considerações finais, faz-se necessário apontar dois limites em estudos como este aqui realizado: de um lado, a existência de artigos sobre o tema que não aparecem nestas plataformas por terem sido publicados em revistas a elas não indexadas; e, por outro, a possibilidade do uso de outros descritores por autores que trabalhem nesta temática. Assim, apesar de o levantamento ter considerado 62 combinações possíveis de descritores, pode ocorrer que algum artigo tenha escapado, pelo fato de o autor ter escolhido outros descritores.

A partir do delineamento dos dados aqui levantados, e da análise de cada um dos artigos considerados, foi possível observar que o tema da saúde mental em contextos indígenas ainda sofre grande escassez de produção acadêmica. No total foram levantados 5510 artigos, sendo apenas 14 , ou seja, $0,2 \%$ afinados com o tema. Este quadro revela um resultado pífio de publicações na área pluridisciplinar de saúde mental em contextos indígenas no período de 1999 a 2012.

Não apenas as pesquisas sobre saúde mental entre os povos indígenas no Brasil são escassas, mas os poucos artigos encontrados demonstraram, em sua grande maioria, pouca reflexão teórica e epistemológica sobre o uso das categorias saúde mental (e correlatos) e indígena. Também foi possível observar que existem poucas produções de cunho teórico. Não se trata de desqualificar as pesquisas de campo, mas de ressaltar a possibilidade de uma prática sem rigor teórico tornar-se cega e etnocêntrica.

É imprescindível que haja consistência e reflexão teórica e epistemológica para avanços nas possibilidades de diálogo com esses povos. Fica evidente, assim, a necessidade de políticas públicas que incentivem o aumento do número de pesquisas sobre e com os povos indígenas, tanto em trabalhos de campo, como em afinações conceituais necessárias para uma melhor sintonia às diversas realidades étnico-culturais. Neste sentido, trata-se de pensar não apenas nos aportes (e suas limitações) que podemos oferecer a estes povos, mas também na infindável riqueza que eles têm a nos oferecer mostrando as limitações de nossos próprios conceitos.

Além disso, ao pensarmos nas publicações voltadas e compostas pela área psi dentro da saúde mental, pode-se afirmar que, mesmo que a demanda por um olhar psi para questões de saúde mental em contextos indígenas (CRPSP, 2010) esteja crescendo, ainda são poucos profissionais psicólogos e departamentos de psicologia que estão engajados na pesquisa desse tema. Se observarmos o total de artigos levantados (14), 50\% contaram com a participação de psicólogos. Por mais que metade das produções tenham contado com a presença desse profissional, o valor bruto de trabalhos é muito pequeno, apenas sete artigos. Se pensarmos que o levantamento abrangeu 13 anos de pesquisa, não daria ao menos um artigo por ano.

Finalmente, destaca-se a necessidade da interdisciplinaridade neste campo, podendo a psicologia aportar contribuições importantes, por meio de uma escuta qualificada do sofrimento/aflição, em uma clínica redimensionada por um perspectivismo cultural. 


\section{Referências}

IV Conferência Internacional de Saúde Mental Indígena (2007). Relatório final. Brasília: Funasa.

Andrade, V. M., \& Bueno, O. F. A. (2007). Neuropsicologia transcultural: grupo indígena Guarani. Estudos de Psicologia, 12(3), 253-258. doi: 10.1590/S1413-294X2007000300007

Azevêdo, P. V. B, Caixeta, L., Andrade, L. H. S., \& Bordin, I. A. (2010). Attention deficit/hyperactivity disorder symptoms in indigenous children from the Brazilian Amazon. Arquivos de Neuro-Psiquiatria, 68(4), 541-544. doi: 10.1590/S0004-282X2010000400012

Bonfim, T. E. (2011). Avaliação psicológica e saúde mental: aplicações da psicologia clínica em comunidades indígenas. Psicólogo in Formação, 15(15), 155-168. doi: 10.15603/2176-0969/ pi.v15n15p155-168

Cantele, J., Arpini, D. M., \& Roso, A. (2012). A psicologia no modelo atual de atenção em saúde mental. Psicologia, Ciência e Profissão, 32(4), 910-925. doi: 10.1590/S1414-98932012000400011

Centro Brasileiro de Estudos Latino Americanos (2014). Mapa da violência. Recuperado de www.mapadaviolencia.org.br

Conselho Indigenista Missionário (2013). Relatório: violência contra os povos indígenas no Brasil. Recuperado dehttp://cimi.org.br/pub/ RelatorioViolencia_dados_2013.pdf

Conselho Regional de Psicologia da 6 ${ }^{\underline{a}}$ Região (Org.) (2010). Psicologia e povos indígenas. São Paulo: CRPSP.

Cunha, A. G. (1986). Dicionário etimológico nova fronteira da língua portuguesa ( $2^{\mathrm{a}}$ ed.). Rio de Janeiro: Nova Fronteira.

Diehl, E. E., \& Grassi, F. (2010). Uso de medicamentos em uma aldeia Guarani do litoral de Santa Catarina, Brasil. Cadernos de Saúde Pública, 26(8), 1549-1560. doi: 10.1590/S0102311X2010000800009

Esperanza, G. (2011). Medicalizar a vida. In A. Jerusalinky \& S. Fendrik (Orgs.), O livro negro da psicopatologia contemporânea (pp. 53-59). São Paulo: Via Lettera.

Foucault, M. (1973). O poder psiquiátrico. São Paulo: Martins Fontes.

Grubits, S., Freire, H. B. G., \& Noriega, J. A. V. (2011). Suicídios de jovens Guarani/Kaiowá de Mato Grosso do Sul, Brasil. Psicologia: Ciência e Profissão, 31(3), 504-517. 10.1590/S1414-98932011000300006

Guimarães, L. A., \& Grubits, S. (2007). Alcoolismo e violência em etnias indígenas: uma visão crítica da situação brasileira. Psicologia \& Sociedade, 19(1), 45-51. doi: 10.1590/S0102-71822007000100007

Jerusalinski, A., \& Fendrik, S. (Orgs.) (2011). O livro negro da psicopatologia contemporânea (pp. 29-37). São Paulo: Via Lettera.

José, E. N.S. (2010). Encontro como povo Sateré-Mawé para um diálogo intercultural sobre a loucura (Tese de doutorado). Universidade de São Paulo, São Paulo, SP. doi: 10.11606/T.59.2010.tde-23102013153833

Kirmayer, L. J. (2006). Beyond the "new cross-cultural psychiatry": cultural biology, discursive psychology and the ironies of globalization. Transcultural Psychiatry, 43(1), 126-144. doi: $10.1177 / 1363461506061761$

Kirmayer, L. J. (2009). Cérebros, corpos e pessoas em movimento: a nova psiquiatria cultural e as ironias da globalização. In E. Lechner (Org.), Migração, saúde e diversidade cultural (pp. 63-83). Lisboa: Imprensa de Ciências Sociais.
Kleinman, A. (1978). Concepts and a model for the comparison of medical system as cultural systems. Social Science and Medicine, 12, 85-93. doi: 10.1016/0160-7987(78)90014-5

Kleinman, A. (1991). Rethinking psychiatry: from cultural category to personal experience. Nova lorque: Free Press.

Langdon, E.J., \& Garnelo, L. (Orgs.) (2004). Saúde dos povos indígenas: reflexões sobre antropologia participativa. Rio de Janeiro: Contra Capa Livraria/Associação Brasileira de Antropologia.

Lechner, E. (Org.) (2009). Migração, saúde e diversidade cultural. Lisboa: ICS.

Littlewood, R. (1990). From categories to contexts: a decade of the new cross-cultural psychiatry. British Journal of Psychiatry, 156(3), 308327. doi: 10.1192/bjp.156.3.308

Martinez-Hernáez, A. (2000). What's Behind the symptom? On psychiatric observation and anthropological understanding (Vol. 6).Amsterdam: Harwood Academic.

Martins, F. (2003). Psicopathologia II - Semiologia Clínica. Brasília: Laboratório de Psicopatologia e Psicanálise. Brasília: ABRAFIPP.

Melo, J. R. F.; Maciel, S. C.; Oliveira, R. C. C., \& Silva, A. O. (2011). Implicações do uso do álcool na comunidade indígena Potiguara. Revista de Saúde Coletiva, 21(1), 319-333. doi: 10.1590/S010373312011000100019

Ministério da Saúde. (2004). Secretaria-Executiva. Secretaria de Atenção à Saúde. Legislação em saúde mental: 1990-2004 (5ª ed.). Brasília: Autor.

Neto, F. K., \& Calazans, R. (Orgs.) 2012. Psicopatologia em debate: controvérsias sobre os DSMs. Barbacena: UEMG.

Portaria ํㅡ 2759 de 25 de outubro de 2007 (2007). Estabelece diretrizes gerais para a Política de Atenção Integral à Saúde Mental das Populações Indígenas e cria o Comitê Gestor. Brasília, DF: Ministério da Saúde.

Rodrigues, E., \& Carlini, E. A. (2006). Plantas com possíveis ações psicoativas utilizadas pelos índios Krahô, Brasil. Revista Brasileira de Psiquiatria, 28(4), 277-282. doi: 10.1590/S151644462006005000014

Souza, M. L. P., Deslandes, S. F., \& Garnelo, L. (2010). Modos de vida e modos de beber de jovens indígenas em um contexto de transformações. Ciência e Educação, UNESP, 15(3), 709-716. doi: $10.1590 /$ S1413-81232010000300013

Souza, M. L. P., \& Garnelo, L. (2006). Desconstruindo o alcoolismo: notas a partir da construção do objeto de pesquisa no contexto indígena. Revista Latino-Americana de Psicopatologia Fundamental, 9(2), 279-292. doi: 10.1590/1415-47142006002007

Souza, M. L. P., \& Garnelo, L. (2007). Quando, como e o que se bebe: o processo de alcoolização entre populações indígenas do alto Rio Negro, Brasil. Cadernos de Saúde Pública, 23(7), 1640-1648. doi: 10.1590/S0102-311X2007000700015

Souza, M.L.P., \& Orellana, J. D.Y. (2012). Suicide mortality in São Gabriel da Cachoeira, a predominantly indigenous Brazilian municipality. Revista Brasileira de Psiquiatria, 34(1), 34-37. doi: 10.1590/S151644462012000100007

Souza, M. L. P., Schweickardt, J. C., \& Garnelo, L. (2007). O processo de alcoolização em populações indígenas do Alto Rio Negro e as limitações do CAGE como instrumento de screening para dependência ao álcool. Revista de Psiquiatria Clínica, 34(2), 90-96. doi: 10.1590/S0101-60832007000200005 
Saúde mental em contextos indígenas

Stock, B. S. (2010). A alegria é a prova dos nove: o devir-ameríndio no encontro com o urbano e a psicologia (Dissertação de mestrado). Universidade Federal do Rio Grande do Sul, Porto Alegre, RS. Recuperado de http://hdl.handle.net/10183/27015

Vianna, J. J., Cedaro, J. J., \& Ott, A. M. (2012). Aspectos psicológicos na utilização de bebidas alcoólicas entre os karitiana. Psicologia \& Sociedade,24(1), 94-103. doi: 10.1590/S0102-71822012000100011
Vitale, M. P., \& Grubits, S. (2009). Psicologia e povos indígenas: um estudo preliminar do "Estado da Arte". Revista Psicologia e Saúde, 1(1), 15-30. Recuperado de http://www.gpec.ucdb.br/pssa/index. $\mathrm{php} / \mathrm{pssa} /$ article/view/10

Yap, P. M. (1951). Mental diseases peculiar to certain cultures: a survey of comparative psychiatry. In R. Littlewwod \& S. Dein (Orgs.), Cultural psychiatry \& medical anthropology (pp. 179-196). Londres: The Athlone Press.

${ }^{1}$ McGill - Canadá; Ceas/ISCTE- Portugal; Berkeley - EUA; Paris 13 - França; Paris VIII - França; Universidade de Turim - Itália; UniversityCollege London - Inglaterra; Harvard - EUA; entre outras.

Marianna Queiróz Batista, Mestre em Psicologia Clínica e Cultura pela

Universidade de Brasília (UnB), Psicóloga da Secretaria de Estado de Educação do Distrito Federal (SEE-DF). Endereço para correspondência: SHDB QL32 Conj 14 Casa 01. CEP 71676-170. Brasília-DF. Telefone: 3367-5337(fixo); 99267-6082 (celular).E-mail: mariq82@gmail.com

Valeska Zanello, Doutora em Psicologia Clínica pela Universidade de Brasília (UnB), com período sanduíche na Université Catholique de Louvain/Bélgica, é Professora Adjunta do Departamento de Psicologia Clínica da Universidade de Brasília (UnB) e orientadora do Programa de Pós-Graduação em Psicologia Clínica e Cultura da Universidade de Brasília (UnB). E-mail: valeskazanello@uol.com.br

Recebido em 07.Mai.15

Revisado em 06.Jul.16

Aceito em 16.Nov.16 